\title{
Low-Level Jets over the Mid-Atlantic States: Warm-Season Climatology and a Case Study
}

\author{
Da-Lin Zhang, Shunli Zhang, and Scott J. Weaver \\ Department of Atmospheric and Oceanic Science, University of Maryland, College Park, College Park, Maryland
}

(Manuscript received 8 March 2005, in final form 2 June 2005)

\begin{abstract}
Although considerable research has been conducted to study the characteristics of the low-level jets (LLJs) over the Great Plains states, little is known about the development of LLJs over the Mid-Atlantic states. In this study, the Mid-Atlantic LLJ and its associated characteristics during the warm seasons of 2001 and 2002 are documented with both the wind profiler data and the daily real-time model forecast products. A case study with three model sensitivity simulations is performed to gain insight into the three-dimensional structures and evolution of an LLJ and the mechanisms by which it developed. It is found that the Mid-Atlantic LLJ, ranging from 8 to $23 \mathrm{~m} \mathrm{~s}^{-1}$, appeared at an average altitude of $670 \mathrm{~m}$ and on 15-25 days of each month. About $90 \%$ of the 160 observed LLJ events occurred between 0000 and 0600 LST, and about $60 \%$ had southerly to westerly directions. Statistically, the real-time forecasts capture most of the LLJ events with nearly the right timing, intensity, and altitude, although individual forecasts may not correspond to those observed. For a selected southwesterly LLJ case, both the observations and the control simulation exhibit a pronounced diurnal cycle of horizontal winds in the lowest $1.5 \mathrm{~km}$. The simulation shows that the Appalachian Mountains tend to produce a sloping mixed layer with northeasterly thermal winds during the daytime and reversed thermal winds after midnight. With additional thermal contrast effects associated with the Chesapeake Bay and the Atlantic Ocean, the daytime low-level winds vary significantly from the east coast to the mountainous regions. The LLJ after midnight tends to be peaked preferentially around $77.5^{\circ} \mathrm{W}$ near the middle portion of the sloping terrain, and it decreases eastward as a result of the opposite thermal gradient across the coastline from the mountain-generated thermal gradient. Although the Mid-Atlantic LLJ is much weaker and less extensive than that over the Great Plains states, it has a width of 300-400 km (to its half-peak value) and a length scale of more than $1500 \mathrm{~km}$, following closely the orientation of the Appalachians. Sensitivity simulations show that eliminating the surface heat fluxes produces the most significant impact on the development of the LLJ, then topography and the land-sea contrast, with its area-averaged intensity reduced from $12 \mathrm{~m} \mathrm{~s}^{-1}$ to about 6,9 , and $10 \mathrm{~m} \mathrm{~s}^{-1}$, respectively.
\end{abstract}

\section{Introduction}

A low-level jet (LLJ) is typically defined as a wind speed maximum of more than $12 \mathrm{~m} \mathrm{~s}^{-1}$ between 500 and $1500 \mathrm{~m}$ above the ground level (AGL), and it is primarily a nocturnal phenomenon that occurs more frequently during the spring and summer seasons. This phenomenon was first noted in the late 1930s over Africa (Farquharson 1939), and later frequently reported over North and South America, Australia, Asia, Antarctica, and elsewhere (Zemba and Friehe 1987; Bonner 1968; Enfield 1981; Parish et al. 1988). The genera-

Corresponding author address: Dr. Da-Lin Zhang, Department of Atmospheric and Oceanic Science, University of Maryland, College Park, College Park, MD 20742.

E-mail: dalin@atmos.umd.edu tion mechanisms of LLJs and their effects on many meteorological problems have been extensively studied in theory, observations, and numerical models (e.g., Blackadar 1957; Wexler 1961; Holton 1967; Paegle and McLawhorn 1983), particularly for the LLJs that occurred frequently over the Great Plains states (Hoecker 1963; Fast and McCorcle 1990; Zhong et al. 1996).

Theoretical analysis of LLJs began with the work of Blackadar (1957), who showed that a supergeostrophic LLJ could develop, following the rotation of an inertial oscillation in the planetary boundary layer (PBL), which is initiated by a sudden decoupling from the surface friction near sunset. Such an LLJ tends to appear near the top of a surface-based inversion after midnight. Holton (1967) described the nature of LLJs as a response to the diurnal heating and cooling cycle of 
sloping terrain, leading to a periodic variation in thermal wind and a consequent low-level geostrophic wind oscillation. This mechanism explains why some LLJs develop over the gently sloping Great Plains, and they cannot be addressed by Blackadar's theory. Wexler (1961) considered the formation of LLJs over the Great Plains as a consequence of the blocking effect of the Rockies such that the low-level westward-moving air is forced northward-an atmospheric analogy to the Gulf Stream. Uccellini and Johnson (1979) emphasized the importance of mass adjustment in the development of an LLJ, as a return branch of an indirect transverse circulation, beneath the exit region of the uppertropospheric jet streak.

Many of the previous observational studies have documented the three-dimensional (3D) structures and evolution of LLJs over the Great Plains, for example, using the twice-daily rawinsonde data (Bonner 1968) or the hourly wind profiler data (Mitchell et al. 1995). Whiteman et al. (1997) provided a detailed climatological description of LLJs over north-central Oklahoma using the 2-yr special research rawinsonde data with enhanced temporal resolution. They showed that the LLJs they studied were stronger than those previously reported and that the altitudes of the LLJ core are closer to the ground. This result suggests the significance of using higher vertical and temporal resolution data in examining the structures and evolution of LLJs.

The subject of LLJs has drawn considerable attention not only because of the interesting phenomenon, but also because of their effects on the weather, aviation safety, and regional climate. Numerous studies have shown that LLJs are closely correlated with deep convection and nocturnal precipitation (Means 1944; Wallace 1975: Bosart and Sanders 1981; Zhang and Fritsch 1986), and they appear to be an essential ingredient in the environment favoring the development of mesoscale convective complexes (MCCs; Maddox 1983). This is because LLJs tend to enhance the advection of warm, moist air in the lower troposphere, causing potential instability. The important impact of LLJs on regional climate has been examined by Higgins et al. (1997), who found that the low-level moisture flux from the Gulf of Mexico at night would be increased by $48 \%$ from its mean value in the presence of an LLJ. For instance, the widespread Great Plains flooding event of 1993 was associated with a prolonged period of strong LLJs (Arritt et al. 1997). In contrast, in the drought episode of 1988, the Great Plains LLJs were only about half as strong as those of 1993 (Mo et al. 1995). Stensrud (1996) reviewed a number of the previous LLJ studies and also pointed out the important contributions of LLJs to regional climate.
Despite the considerable attention of LLJs over the Great Plains during the past 5 decades, little is known about the development of LLJs along the east coastal region of the United States during the spring and summer seasons. As compared with the Great Plains states, where the Rocky Mountains are located to the west, the east coastal region is situated to the east of the Appalachian Mountains and to the west of the Atlantic Ocean. The geographic characteristics are favorable for generating shallow baroclinicity, and they must have some impact on the 3D structures and evolution of the low-tropospheric flows. Thus, the objectives of this study are to (a) document the characteristics of LLJs over the Mid-Atlantic states using the high-resolution wind profiler data that were taken at Fort Meade, Maryland, and the real-time model prediction data both during the warm seasons of 2001 and 2002; (b) compare statistically the model-predicted LLJ events with those observed in order to establish credibility for using these forecast data to study various nonobservable meteorological features and air quality problems, including the related LLJs; and (c) perform a modeling case study of a typical LLJ using the fifth-generation Pennsylvania State University-National Center for Atmospheric Research Mesoscale Model (MM5) in order to examine the 3D structures and evolution of the MidAtlantic LLJ as well as the factors involved in its development. We are also motivated to conduct this study because of the significance of LLJs in transporting chemical constituents that are trapped in the residual layer at night.

The next section describes the observational data taken at Fort Meade, and the major model features used for the real-time daily weather prediction at the Department of Atmospheric and Oceanic Science (AOSC), University of Maryland (UMD), and for the case study to be presented in sections 4 and 5. Section 3 documents and compares the observed and modelpredicted climatologies of LLJs during the warm seasons of 2001 and 2002. Section 4 shows a 60-h modeling case study of the LLJ that occurred on 18-21 June 2001. Characteristics of the LLJ and its diurnal cycle will be compared with the flow regimes occurring over the eastern two-thirds of the United States. Section 5 analyzes the sensitivity of the modeled LLJ to the surface heat fluxes, topography, and the land-sea contrasts. A summary and concluding remarks are given in the final section.

\section{Data processing and model description}

Observational data used for this study were acquired from Maryland's Department of Environment wind profiler that is located at Fort Meade $\left(39.11^{\circ} \mathrm{N}\right.$, 
$76.71^{\circ} \mathrm{W}$ ) (see Fig. 1 for the location). It has a frequency of $915 \mathrm{MHz}$ and a wavelength of $32.8 \mathrm{~cm}$, with a peak transmittance power of $500 \mathrm{~W}$. The profiler measures virtual temperature in the first $5 \mathrm{~min}$ of each hour, and wind speed and direction for the remaining $55 \mathrm{~min}$ within the errors of $1 \mathrm{~m} \mathrm{~s}^{-1}$ and $10^{\circ}$, respectively, under normal weather situations. The wind data, averaged at 30-min and 55-m intervals, are available up to an altitude of $2-5 \mathrm{~km}$, depending on the atmospheric conditions, with the lowest gate of $120 \mathrm{~m}$. However, only the lowest $1.5 \mathrm{~km}$ of data are used for this study because of reliability and consistency considerations.

Since 1998, experimental real-time 48-h forecasts of regional weather conditions have been provided, like several other universities (see Mass and Kuo 1998), by AOSC-UMD to the public through its Web site (see information online at http://www.atmos.umd.edu/ $\sim$ mm5), using the MM5. Some selected model outputs have been archived at hourly intervals in order to (a) help to improve the understanding of certain mesoscale processes from the east coast to the mountainous regions, including LLJs in the Mid-Atlantic states; and (b) study various air quality and atmospheric deposition problems. The major model features of MM5 used for the real-time daily forecasts and for the present case study include (a) nonhydrostatic dynamics with twoway interactive nested-grid $(36 / 12 / 4 \mathrm{~km})$ procedures (Dudhia 1989; see Fig. 1 for the 12-km-resolution domain), (b) $24 \sigma$ layers in the vertical with a surface layer of $24 \mathrm{~m}$ and radiative top-level boundary conditions at $50 \mathrm{hPa}$, (c) the Blackadar high-resolution PBL parameterization (Zhang and Anthes 1982), (d) explicit cloud physics with simple ice microphysics (Dudhia 1989; Zhang 1989), and (e) the modified Kain-Fritsch (Kain and Fritsch 1990) cumulus parameterization. The realtime forecasts were initialized at 0000 UTC daily with the National Centers for Environmental Prediction (NCEP) Eta Model analysis. The model $(x, y)$ dimensions for the 36-, 12-, and 4-km-resolution domains are $73 \times 97,70 \times 88$, and $85 \times 103$, respectively. The outermesh domain covers two-thirds of the United States and part of Canada, that is, extending from Nova Scotia to northwestern Montana and from central Florida to southern Hudson Bay (not shown). There are eight model layers in the lowest $1.5 \mathrm{~km}$ that are roughly located at 12, 50, 120, 240, 430, 720, 1090, and $1520 \mathrm{~m}$ AGL.

Model outputs after the first 24-h forecasts from the fine-mesh domain (see Fig. 1) are used to investigate the structures and evolution of LLJs over the MidAtlantic states because of the consistency considerations for the sensitivity simulations to be presented in section 5. To compare with the wind profiler data, the

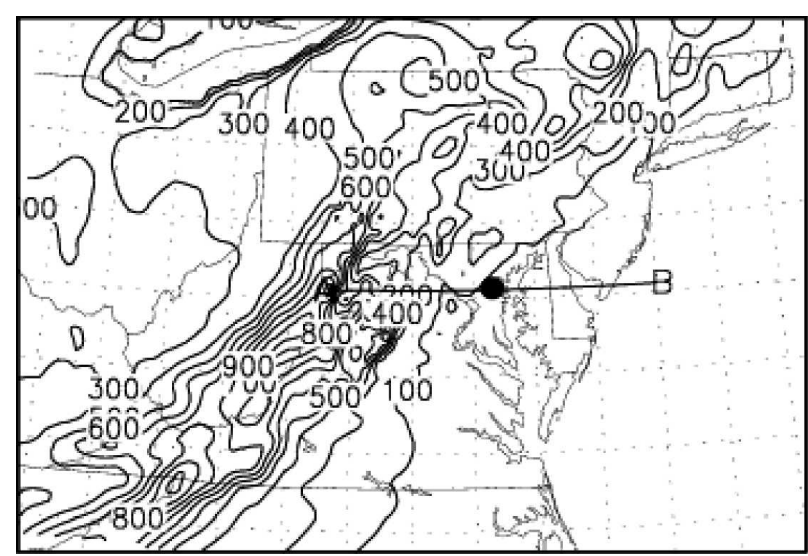

FIG. 1. Topography, at intervals of $100 \mathrm{~m}$, in the fine-mesh (12-km resolution) model domain. The large dot denotes the location of the Fort Meade $\left(39.11^{\circ} \mathrm{N}, 76.71^{\circ} \mathrm{W}\right)$ wind profiler. Line $\mathrm{AB}$ shows the location of cross sections used in Figs. 9 and 11.

model-predicted winds are interpolated to the location of Fort Meade, and the wind directions are adjusted from the model $(x, y)$ coordinates with Lambert conformal projection to the local latitude-longitude coordinates.

To identify the presence of LLJs, daily plots of the height-time cross sections of horizontal winds from both the wind profiler data and model outputs are visually examined for the warm seasons of 2001 (i.e., from 1 May to 30 September) and 2002 (from 1 June to 31 August). A shorter period for the year of 2002 is used owing to the lack of wind profiler observations in the months of May and September. Then, the vertical jetlike structures in the lowest $1.5 \mathrm{~km}$ are identified with positive shear below and negative shear above at 300-m intervals. Such a broad definition of LLJs is necessary because a single station could not frequently capture the core of LLJs, as will be seen in section 4. Thus, we define an LLJ in this study simply as any lowertropospheric maximum in the vertical profile of the horizontal wind speeds.

\section{Warm-season climatology}

To document the characteristic of LLJs, five key parameters of LLJs are analyzed from both the observed and model data, which include the (a) height, (b) magnitude, (c) direction (in degrees), (d) timing of occurrence, and (e) negative shear estimated as speed differences in the 300-m interval above the local wind maximum.

\section{a. The warm season of 2001}

Figure 2 compares the scatterplots of the above five key parameters of LLJs between those observed and modeled during the months of May-September 2001, 

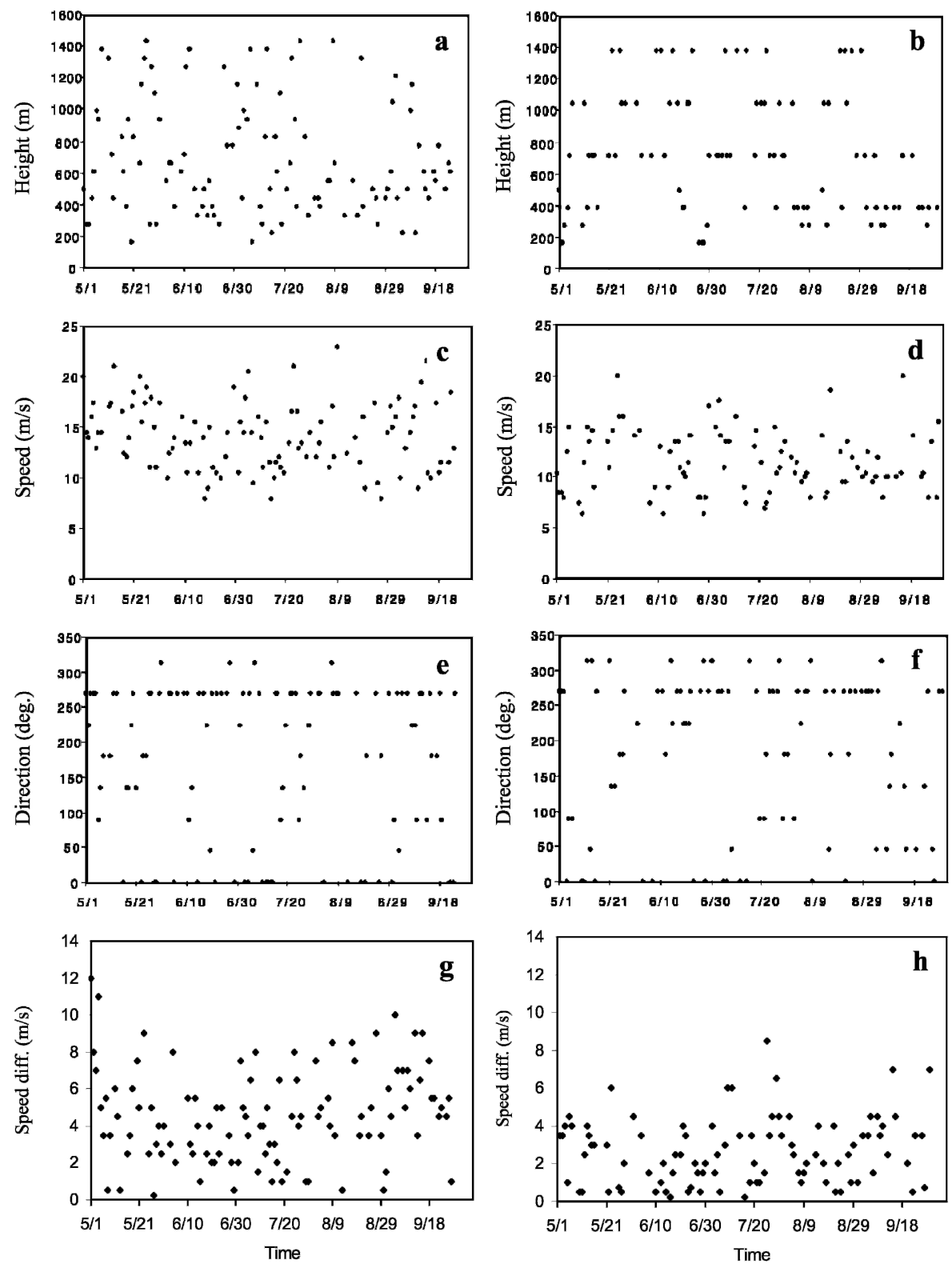

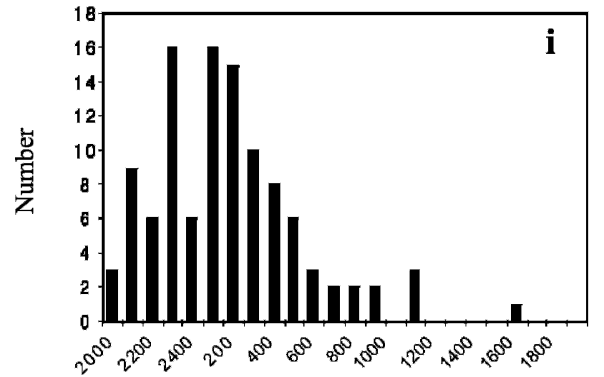

Time (LST)

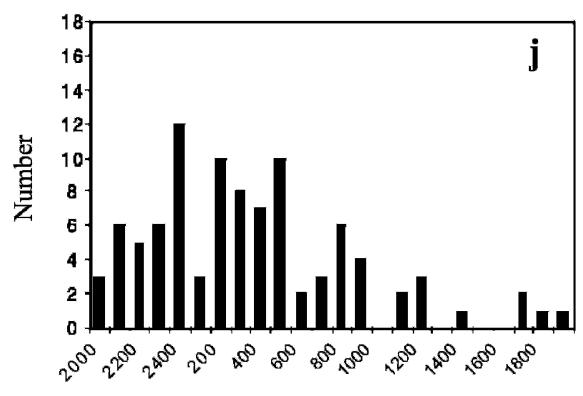

Time (LST)

FIG. 2. Comparison of scatterplots of the (a), (b) height (m), (c), (d) magnitude ( $\mathrm{m} \mathrm{s}^{-1}$ ), and (e), (f) direction $\left({ }^{\circ}\right)$ of LLJs; $(\mathrm{g})$, (h) the vertical shear represented by the speed difference at a $300-\mathrm{m}$ interval above the LLJs core; and (i), (j) the number of the LLJ occurrences as a function of LST for the months of May-September 2001. The left (right) panel is for the observed (modeled) events. 
TABLE 1. Statistical comparisons of the observed and modeled LLJ events for the 2001 warm season (1 May-20 Sep). The number of the LLJ events of greater than $12 \mathrm{~m} \mathrm{~s}^{-1}$ is given in parentheses.

\begin{tabular}{lcc}
\hline \hline \multicolumn{1}{c}{ Parameter } & Observed & Modeled \\
\hline Total LLJ events & $108(70)$ & $95(38)$ \\
Events occurred during 0000-0600 LST & 71 & 52 \\
Southerly to westerly events & 64 & 52 \\
Average height (m) & 688 & 727 \\
Average speed $\left(\mathrm{m} \mathrm{s}^{-1}\right)$ & 14 & 11.5 \\
\hline
\end{tabular}

and Table 1 summarizes their statistics. A total of 108 LLJ events with an average wind speed of $14 \mathrm{~m} \mathrm{~s}^{-1}$ were observed at Fort Meade (cf. Figs. 2c and 4a), 70 of which meet the typical LLJ definition of $12 \mathrm{~m} \mathrm{~s}^{-1}$. The negative shear above the LLJ core varied mostly from 2 to $7 \mathrm{~m} \mathrm{~s}^{-1}$ in a $300-\mathrm{m}$ interval with an average value of $4.7 \mathrm{~m} \mathrm{~s}^{-1}$ (Fig. 2g). Although the duration of these events differed considerably, $71 \%$ occurred late at night (Fig. 2i), that is, between 0000 and 0600 LST (or 0400 and 1000 UTC) (see Table 1). This is consistent with the inertial oscillation theory that predicts the most frequent development of LLJs late at night. Of the LLJ events, $59 \%$ had a wind direction in the southwest quadrant (i.e., from $180^{\circ}$ to $270^{\circ}$, see Fig. 2e). The average height of the LLJ occurrences was $688 \mathrm{~m}$ AGL, with significant events concentrated around $400 \mathrm{~m}$ and about $15 \%$ of the events occurring above $1 \mathrm{~km}$ (Fig. 2a).

The real-time forecasts capture 95 LLJ events during the months of May-September 2001 (Table 1), which represents an $88 \%$ rate of those observed. Of the 95 LLJ events, 53\% occur between 0000 and 0600 LST (Fig. 2j). The average height of LLJs is $727 \mathrm{~m}$, which is close to those observed (Table 1). There are also significant events concentrated near $400 \mathrm{~m}$ (Fig. 2b). Note that the more rigid distribution of the modeled fields, relative to the observed, is a by-product of the coarse vertical resolution (cf. Figs. $2 a, c$ and $2 b$,d). Of importance is that 52 events have a wind direction in the southwest quadrant, supporting the observation that a majority of LLJs tends to be southerly-to-westerly (Figs. 2e,f).

The magnitudes of the predicted LLJs range from 6 to $20 \mathrm{~m} \mathrm{~s}^{-1}$, with an average of $11.5 \mathrm{~m} \mathrm{~s}^{-1}$, as compared with the observed 8-23 $\mathrm{m} \mathrm{s}^{-1}$ range with an average of $14 \mathrm{~m} \mathrm{~s}^{-1}$. Of interest is that most of the observed LLJs were $10-20 \mathrm{~m} \mathrm{~s}^{-1}$, whereas a majority of the modeled LLJs occurs in the range of $8-15 \mathrm{~m} \mathrm{~s}^{-1}$. Some differences also occur in the magnitudes of negative shears above (cf. Figs. $2 \mathrm{~g}$ and $2 \mathrm{~h}$ ). These differences are likely a result of the different vertical resolutions between the two datasets, in addition to the other limitations in the model initial conditions and physics. On average, the real-time forecasts reproduce most of the observed LLJs events for 2001, with a probability of the $82 \%$ hit rate. A comparison of Figs. $2 a$ and $2 b$ shows that the less model skill is more associated with the LLJ events occurring at the lowest levels, particularly for the period of 20 May-20 July. This indicates the possible lack of the realistic representation of surface features in the model, because the LLJ events at higher levels, more associated with the larger-scale meteorological fields, are better reproduced.

Figures $2 \mathrm{i}$ and $2 \mathrm{j}$ compare the times of the observed and modeled LLJ occurrences. Almost all of the observed LLJs took place at night with the peak during the period of 0000-0300 LST. This is generally true of the modeled occurrences. This timing and the average altitude of the LLJ occurrences are consistent with a recent study of the Southern Plains LLJ by Whiteman et al. (1997) who showed that about $50 \%$ of the LLJs occurred below $500 \mathrm{~m}$ and most appeared at 0200 LST. However, there are a notable number of the modeled LLJs occurring in the late-morning hours with a rapid drop in frequency after 0600 LST.

\section{b. The warm season of 2002}

Figure 3 compares the scatterplots of the observed fields with those modeled for the months of JuneAugust 2002. It is encouraging to note that the distributions of LLJ speeds for those observed and modeled are very similar (cf. Figs. $3 \mathrm{c}$ and $3 \mathrm{~d}$ ), which is not the case in 2001. Similarly, the modeled LLJ statistics for 2002 compare more favorably to those observed than those in 2001 (cf. Tables 1 and 2). For instance, the observed average height of the LLJ core was located at $650 \mathrm{~m}$ as compared with that modeled at $641 \mathrm{~m}$ (Table 2). The observed average speed was $13.6 \mathrm{~m} \mathrm{~s}^{-1}$ with a range of $8-21 \mathrm{~m} \mathrm{~s}^{-1}$, as compared with the modeled 12 $\mathrm{m} \mathrm{s}^{-1}$ mean speed with a range of 6-22 $\mathrm{m} \mathrm{s}^{-1}$ (see Table 2 and Figs. 3a,b). On average, the model forecasts have an $86 \%$ probability hit rate of the observed LLJs events for 2002. This improved skill could be attributed to some improvements in NCEP's initial conditions because the model physics used in MM5 are identical in both years. In fact, NCEP did improve its threedimensional variational data assimilation analysis later in 2001, in which satellite radiance in National Oceanic and Atmospheric Administration (NOAA)-16 and Weather Surveillance Radar-1988 Doppler (WSR-88D) radial velocity were included and the land surface assimilation scheme was modified (G. DiMego 2001, personal communication).

From 1 June to 31 August 2002, there were 52 LLJ 

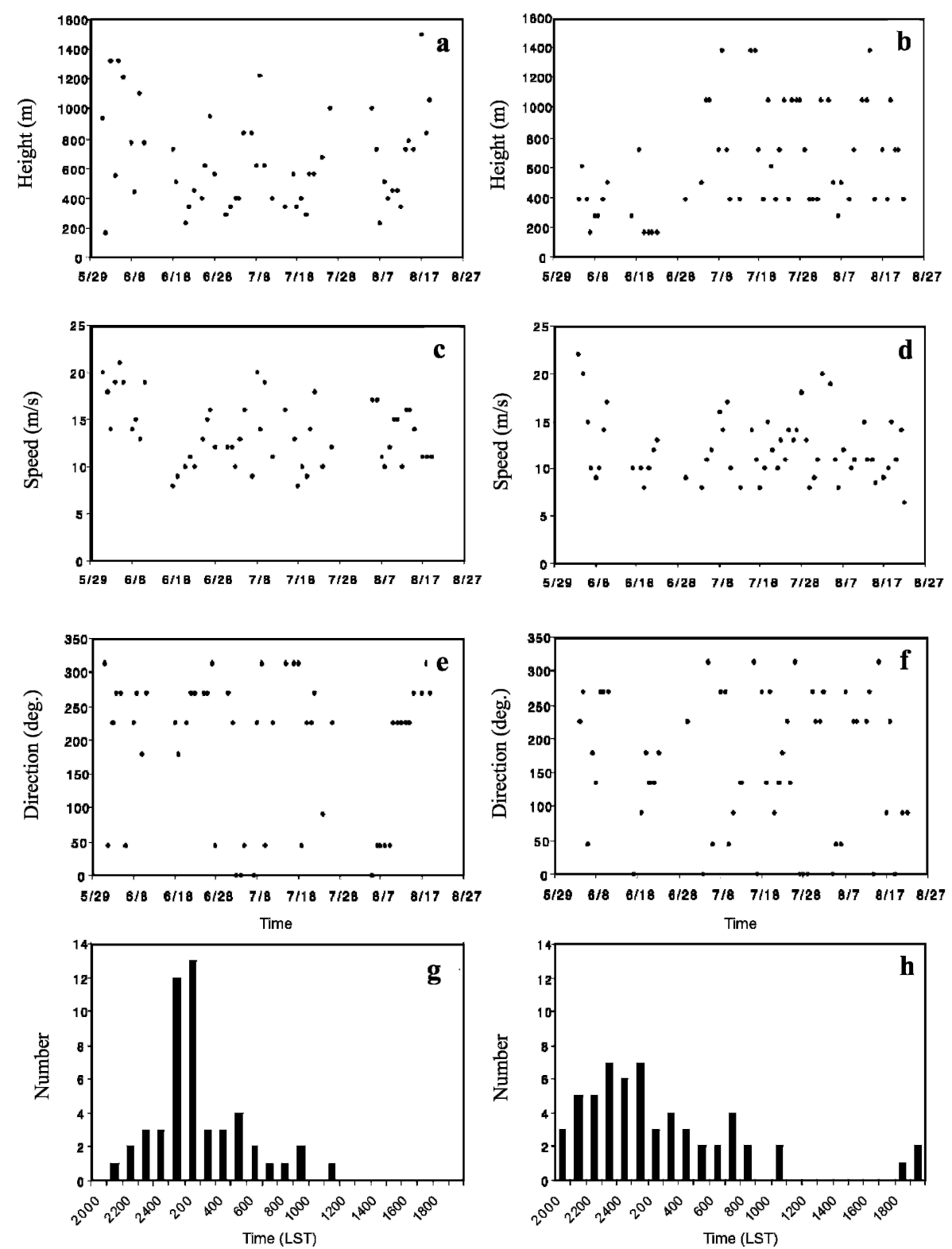

FIG. 3. As in Fig. 2, but for the months of June-August 2002 except that the vertical shear represented by the speed difference at a $300-\mathrm{m}$ interval above the LLJs core is not shown.

events observed at Fort Meade (Table 2), which are only 11 events less than those for the same period in 2001 (cf. Figs. 4a,b). (A total of 45 events occurred in the 2 months of May and September 2001.) On average, an LLJ appeared on 20-25 days of each month during the 2001 warm season, and 15-19 days for the 2002 warm season. The decreased frequency in the LLJ occurrences in 2002 may be attributed to the fact that this was an El Niño year with more cloudy/rainy days in the Mid-Atlantic states. Again, a significant portion (i.e., $50 \%-58 \%$ ) of LLJs had a wind direction in the southwest quadrant, and $54 \%$ of the observed LLJs were greater than $12 \mathrm{~m} \mathrm{~s}^{-1}$ (Table 2). Of interest is that the model resolves 58 LLJ events, which are 6 more than observed, in contrast to the underpredicted LLJ events in the 2001 warm season. Part of this overprediction appears to be attributable to the LLJ occurrences below $300 \mathrm{~m}$ that are often poorly resolved by the wind profiler measurements (cf. Figs. 3a,b).

While the model skill for the warm season of 2002 shows notable improvements in frequency, height, speed, and direction, it does not reproduce well the observed timing of LLJ occurrences (cf. Figs. 3g, h). Specifically, 38 LLJ events or $73 \%$ were observed dur- 
TABLE 2. As in Table 1, but for the 2002 warm season (1 Jun-30 Aug).

\begin{tabular}{lcc}
\hline \multicolumn{1}{c}{ Parameter } & Observed & Modeled \\
\hline Total LLJ events & $52(28)$ & $58(23)$ \\
Events occurred during 0000-0600 LST & 38 & 25 \\
Southerly to westerly events & 30 & 29 \\
Average height (m) & 650 & 641 \\
Average speed (m s$\left.{ }^{-1}\right)$ & 14 & 12 \\
\hline
\end{tabular}

ing 0000-0600 LST, but only 25 LLJ events or $43 \%$ are predicted. In particular, the model is unable to predict the distinct frequency peaks after midnight (i.e., 01000300 LST). Nevertheless, the model captures the general nocturnal occurrences of LLJs in the warm season.

Although the model tends to underpredict the frequency of LLJ occurrences for 2001, it does show significant improvements in 2002, indicating the sufficient ability of MM5 in predicting the occurrences of LLJs in an operational setting. Thus, the real-time-predicted low-level winds could provide additional numerical guidance to local forecasters and operation planners at higher spatial and temporal resolutions. Of course, one should note that each predicted LLJ event, shown in Figs. $2-4$, does not always correspond to an observed one.

It should be pointed out that the frequent occurrences of LLJs that are reported above have received little attention, partly because the Mid-Atlantic states are under the influence of a subtropical high in summer with relatively stable stratification at night, except for those well-organized traveling weather disturbances, and partly because these LLJ events, occurring mostly during the period of 0500-1100 UTC, could hardly be resolved by twice-daily conventional observations. Furthermore, as will be seen in the next section, the LLJs tend to be more pronounced in the middle portion of the sloping terrain and may be underestimated by the Fort Meade wind profiler. However, these LLJ events, though weaker than those previously studied in the other regions, would be of particular interest to some government agencies and those scientists studying the transport of air pollutants [e.g., ozone $\left(\mathrm{O}_{3}\right)$, carbon monoxide $(\mathrm{CO})$, and nitrogen oxides $\left.\left(\mathrm{NO}_{x}\right)\right]$ in this rapidly growing, industrialized region. This is because the LLJ could not only move pollutants all along the eastern seaboard, but could also advect ozone, haze, and precursors from an area not usually thought of as a source region to the other areas.

\section{A case study}

In this section, a 60-h (i.e., 1200 UTC 18 June-0000 UTC 21 June 2001) modeling case study of an LLJ
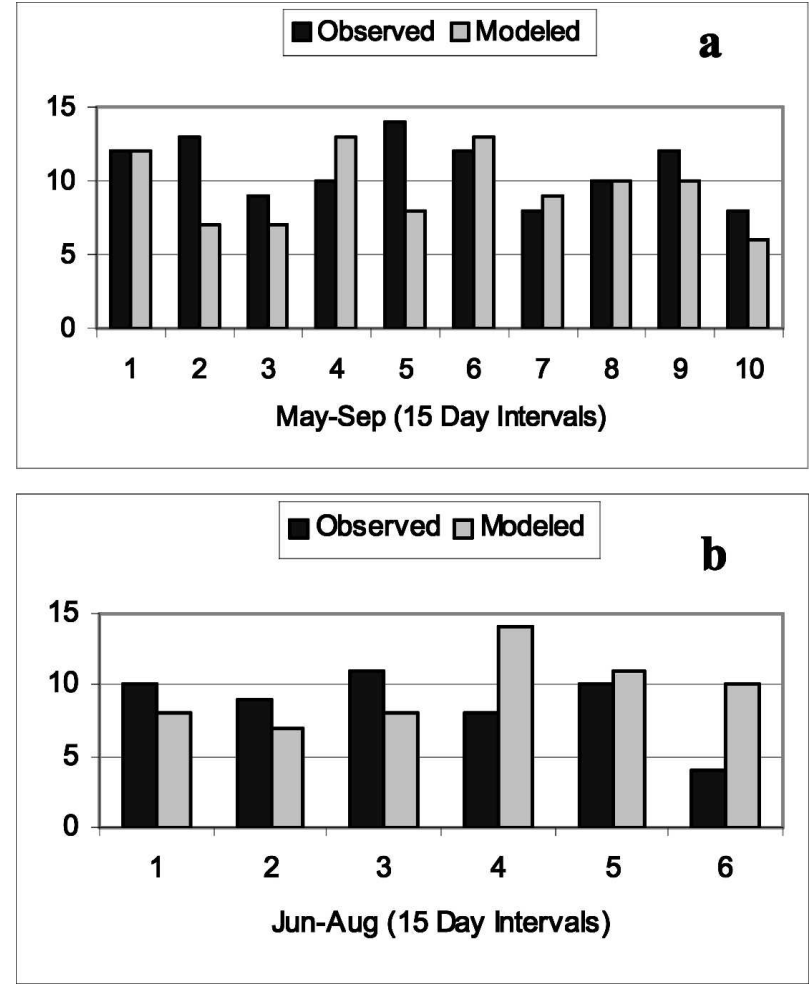

FIG. 4. Observed (dark shaded) and modeled (light shaded) number of LLJ events at 15-day intervals for the warm season of (a) 2001 and (b) 2002 .

event over the Mid-Atlantic states is performed to examine some typical 3D characteristics and evolution. This LLJ event is selected partly because of its southwesterly wind direction, which is a dominant LLJ mode over the Mid-Atlantic states, as shown in the preceding section. Because of few convective activities that occurred over the Mid-Atlantic region during the study period, only two nested-grid domains (i.e., $36 / 12 \mathrm{~km}$ ) are used for the case study (see Fig. 5 for the location of the fine-mesh domain).

Figure 5 shows the large-scale flow conditions in which the 18-21 June LLJ was embedded. A subtropical high pressure system was distributed over the MidAtlantic states. A cold front with a well-defined trough above stretched from Quebec to Illinois and southern Colorado. The trough moved rapidly eastward, and exited the fine-mesh domain in another $12 \mathrm{~h}$ (not shown). A pronounced topographically generated warm tongue extended from the foothills of the Rocky Mountains downstream near sunset but weakened rapidly after midnight. This is typical of the weak-gradient flow observed during the summer months over the eastern twothirds of the United States. Clearly, such a large-scale setting does not have significant influence on the diurnal cycle of the PBL developments over the Great 


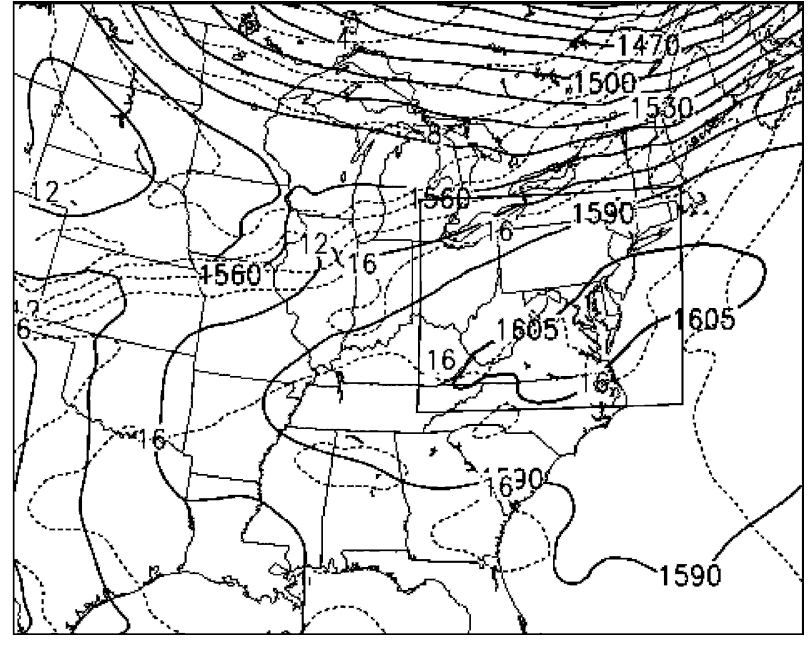

FIG. 5. Horizontal distribution of geopotential height (solid, every $15 \mathrm{~m}$ ) and temperature (dashed, every $2^{\circ} \mathrm{C}$ ) at $850 \mathrm{hPa}$ from the 42-h simulation, valid at 0600 UTC (or 0200 LST) 20 Jun 2001. The internal frame denotes the fine-mesh domain with a $12-\mathrm{km}$ resolution.

Plains and Mid-Atlantic states prior to the passage of the cold front, thus serving as an excellent case for examining various previously mentioned hypotheses on the development of LLJs.

Figure 6 compares the time evolution of the observed wind profiles and the hodograph at the LLJ core level with those simulated during a 24-h period. The observed wind profiles show a pronounced diurnal cycle of horizontal winds with an LLJ occurring after midnight (Fig. 6a). Specifically, the horizontal wind speeds in the lowest $1 \mathrm{~km}$ were about $3-6 \mathrm{~m} \mathrm{~s}^{-1}$ during the early afternoon. They were uniformly distributed with height in the PBL, evidently as a result of vertical mixing by intense turbulent eddies. Wind speeds started to accelerate after sunset (i.e., at about 2000 LST) as they were decoupled from the surface friction, and became the strongest near 0200 LST with a peak value of greater than $13 \mathrm{~m} \mathrm{~s}^{-1}$ (i.e., an LLJ) between 300 and $700 \mathrm{~m}$ AGL. It should be mentioned that this diurnal cycle of the wind variations in the PBL is often opposite in phase to that of surface winds (see Zhang and Zheng 2004). That is, the strongest surface wind occurs at the time of the warmest surface temperature prior to sunset, whereas the weakest surface wind appears at the time of the coldest surface temperature near sunrise when LLJs are often peaked.

Of importance is that the winds in the $300-700-\mathrm{m}$ layer veered with time from southwesterly around sunset to near westerly at midnight and northwesterly in the morning hours. Similar scenarios were repeated the following day. This clockwise turning could be clearly seen from the hodograph covering a diurnal cycle of horizontal winds at the LLJ level (Fig. 6c). This hodograph also shows clearly the acceleration of horizontal winds after sunset and rapid deceleration after sunrise. The changes in wind speed and direction follow closely the inertial oscillation mechanism proposed by Blackadar (1957). A few outliers appeared in the hodograph (e.g., at 1000, 1100, 1600, and 1700 LST 20 June 2001), which may be attributed to the passage of transient weather systems or to the sampling errors resulting from the use of the consensus-averaging algorithm, as pointed out by Augustine and Zipser (1987).

In general, the height-time cross section of the simulated horizontal winds compares favorably to those observed, except for the large departures in wind direction during the afternoon period (cf. Figs. 6a and 6b). The directional departures may be caused by the position errors of the simulated subtropical high because Fort Meade is located near its ridge axis (cf. Figs. 1 and 5). Nevertheless, the model reproduces acceleration of the low-level winds after sunset, the development of the west-southwesterly LLJ at $500 \mathrm{~m}$ AGL after midnight, albeit 1-2 $\mathrm{m} \mathrm{s}^{-1}$ weaker than the observed, the subsequent weakening of the LLJ, and the development of vertically near-constant wind speeds in the well-mixed PBL. The simulated hodograph, given in Fig. 6d, shows well the inertial oscillation schematics of Blackadar (1957), with a clockwise, almost closed circle in $24 \mathrm{~h}$. Note that because of the presence of mean horizontal shear $\partial V / \partial s$, this $24-\mathrm{h}$ period is about $5 \mathrm{~h}$ longer than that of an inertial oscillation determined purely by the local Coriolis parameter, that is, $2 \pi / f$. In this case, the oscillation frequency $F$ in Blackadar's theory for a horizontally sheared environment should be modified as $F=\sqrt{f(f+\partial V / \partial s)}$, and then, the 24-h period $(T=$ $2 \pi / F)$ is equivalent to the presence of a mean anticyclonic horizontal shear of $-3.4 \times 10^{-5} \mathrm{~s}^{-1}$, which is a very reasonable value in the present case. A diurnally averaged geostrophic wind is approximately centered in the circle with subgeostrophic and supergeostrophic winds occurring during the daytime and nighttime hours, respectively. Because the model underpredicts the magnitude of the LLJ core, the radius of the simulated inertial oscillation circle is smaller than those observed (cf. Figs. 6c and 6d). Despite some modeled errors, the general agreements between the modeled and observed wind fields allow us to use the model results to study the characteristics of the Mid-Atlantic LLJ in relation to those occurring elsewhere, and examine the sensitivity to various land surface processes.

Figures $7 \mathrm{a}, \mathrm{b}$ show the distribution of the simulated horizontal winds at $500 \mathrm{~m}$ over the model coarse-mesh subdomain near noon and midnight, respectively, at 

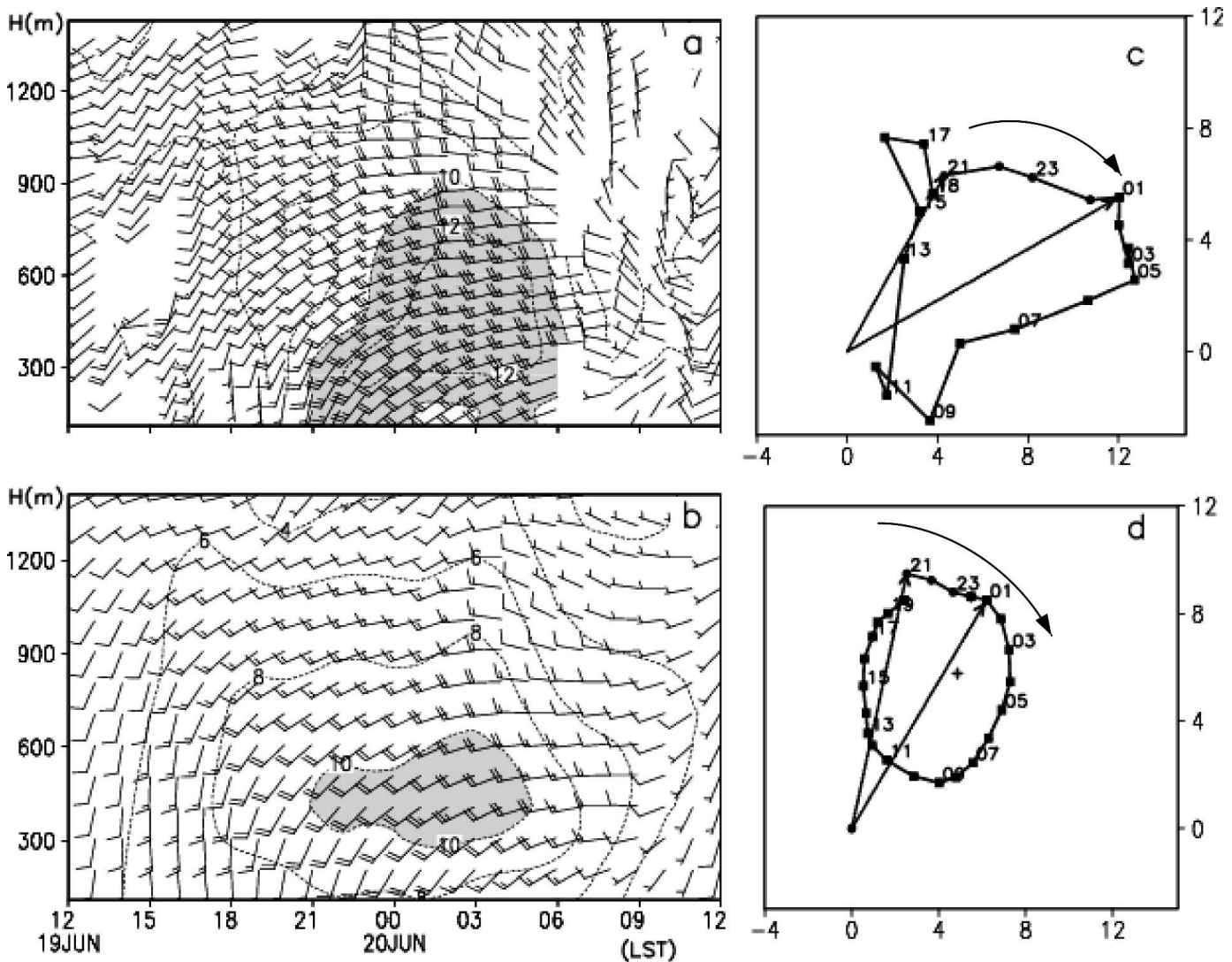

FIG. 6. (left) Time-height cross sections of horizontal winds and isotachs (dotted, every $2 \mathrm{~m} \mathrm{~s}^{-1}$ ) from (a) the wind profiler observations at Fort Meade and (b) those $(28-52 \mathrm{~h}$ ) modeled at the corresponding location for the period of 1200 LST 19 Jun-1200 LST 20 Jun 2001. Shadings denote the layers of horizontal winds exceeding 10 $\mathrm{m} \mathrm{s}^{-1}$. A full barb is $5 \mathrm{~m} \mathrm{~s}^{-1}$. (right) Hodographs at hourly intervals taken at $500 \mathrm{~m}$ AGL from (c) observations and (d) those $(37-60 \mathrm{~h})$ modeled for the period of 2100 LST 19 Jun-2000 LST 20 Jun 2001. Two arrows denote horizontal wind vectors given near sunset and at the time of the peak magnitude. A cross, given in (d), is used to show the magnitude and direction of a diurnally averaged geostrophic wind at $500 \mathrm{~m}$.

which time the two horizontal wind extremes occur. Diurnal variations of the low-level winds over the continent are clearly evident, except for the flows associated with the propagating trough/front along the U.S.Canada border. Specifically, the horizontal winds during the daytime are very weak, mostly less than $4 \mathrm{~m} \mathrm{~s}^{-1}$, from the central United States to the east coast, under the influence of the subtropical high pressure system (Fig. 7a). After midnight, the well-organized anticyclonic flows over most of the regions accelerate, with their magnitudes 2-3 times greater than their daytime values (cf. Figs. 7a,b). An axis of southwesterly LLJs, which is parallel to the Appalachians, stretched from North Carolina to eastern Canada, with much weaker flows occurring to the west (Fig. 7b). This southwestnortheast orientation of the LLJ axis is indicative of the topographically generated baroclinic effect (Holton 1967). As expected, the topographical effect is more pronounced to the east of the Rocky Mountains, where the 500-m winds have increased from 6-8 $\mathrm{m} \mathrm{s}^{-1}$ during the daytime to $14-16 \mathrm{~m} \mathrm{~s}^{-1}$ after midnight. By comparison, the flows are relatively weak over the south central and Midwest regions where little topographical forcing is present. Moreover, little diurnal changes in horizontal winds occur over the oceans (cf. Figs. 7a,b) because of the absence of the surface heating.

To facilitate the comparison with the LLJ obtained at Fort Meade, Fig. 8 shows the height-time cross sections and hodographs of the area-averaged horizontal winds taken at a few representative locations. We noted that except for a few flow regimes (e.g., weak winds, significant baroclinicity, cloudy, over the ocean surface or high plateau), LLJs appear to be ubiquitous over many locations because of the dominant impact of surface radiative heating; but, they differ in magnitude, altitude, timing, and the radius and period of the inertial circles (Figs. 8a-f). To some extent, these differences reflect the relative importance of larger-scale geo- 

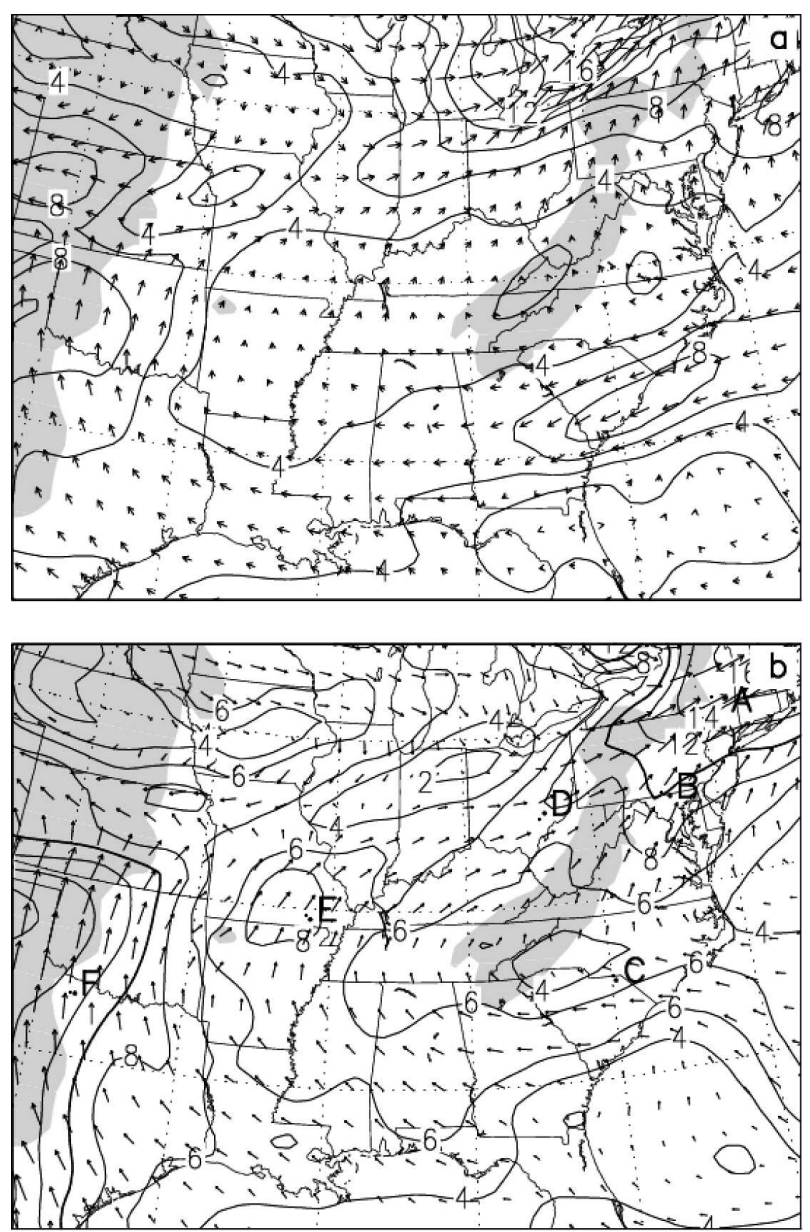

FIG. 7. Horizontal distributions of wind vectors and isotachs (solid, every $2 \mathrm{~m} \mathrm{~s}^{-1}$ ) at $500 \mathrm{~m} \mathrm{AGL}$ from (a) the 30-h prediction valid at 1400 LST 19 Jun, and (b) the 42 -h prediction valid at 0200 LST 20 Jun 2001. Solid circles with letters A-F show the centers at which area averages are performed to examine the vertical profiles of horizontal winds shown in Fig. 8. Shadings denote the distribution of topography.

strophic forcing, the Coriolis parameter, surface heating, and topography. For example, the vertical wind profiles taken to the east of the Appalachians show a similar timing of the LLJ events (i.e., near midnight), but there is an increase in the speed, altitude, and oscillation period of the LLJs from point $C$ northeastward as the horizontal winds change from south-southeasterly to southwesterly and near westerly (Figs. 8a-c). Such increases in speed and altitude are consistent with the northeastward increase in geostrophic winds in the lowest 1-2 km (cf. Figs. 5, 7, and 8a-c). Specifically, the greater the geostrophic wind speed, the larger the ageostrophic component is after sunset as a result of the daytime mixed-layer development. This would in turn produce a larger radius of the inertial circle, according to Blackadar's theory. In addition, stronger LLJs tend to be located at higher altitudes (e.g., $H=250 \mathrm{~m}$ at point $\mathrm{C}, 350 \mathrm{~m}$ at point $\mathrm{B}$, and $600 \mathrm{~m}$ at point $\mathrm{A}$ ) because of the more intense turbulent mixing associated with stronger vertical shear northward. The longer oscillation period from point $\mathrm{C}$ to $\mathrm{A}$ is caused by an increase in anticyclonic shears northeastward, which tends to overcompensate for the effect of the increasing Coriolis parameter. The partial inertial circle at point $\mathrm{D}$ indicates the influence of the propagating trough after 0700 LST (cf. Figs. 5, 7, and 8d).

In contrast, the vertical wind profiles at points $\mathrm{E}$ and F exhibit typical LLJs structures over the Great Plains as examined by many previous studies (e.g., Bonner 1968; Paegle and McLawhorn 1983; Zhong et al. 1996). The LLJ at point $F$, which is the strongest one over the model domain, appears to be a result of the surface heating and the sloping terrain-induced nocturnal horizontal thermal gradients (not shown), as hypothesized by Blackadar (1957) and Holton (1967).

After seeing the diurnal variations of large-scale flows, let us focus on the diurnal characteristics of the lower-tropospheric winds in the Mid-Atlantic states. For this purpose, Figs. 9a,b show the zonal vertical structures of the horizontal winds and potential temperature fields through Fort Meade in the afternoon and after midnight, respectively. In general, the regional winds above $H=600 \mathrm{~m}$ decrease with height during this simulation period due partly to the presence of (weak) westward thermal gradients or northeasterly thermal winds (cf. Figs. 6, 7, and 9). In addition, little diurnal changes in wind speed (i.e., at $1-3 \mathrm{~m} \mathrm{~s}^{-1}$ ) occur near the PBL top or at $H=1800 \mathrm{~m}$. During the afternoon hours, a well-mixed PBL with a depth of 1000$1500 \mathrm{~m}$ develops over land (Fig. 9a). The sloping mixedlayer depth is indicative of the elevated terrain effects of the Appalachians. The mountain waves produce pronounced fluctuations in wind speeds in the vertical with larger shears near the top of the mixed layer. Nevertheless, the turbulent mixing leads to the relative uniform distribution of weak southerly winds, ranging from 4 to $6 \mathrm{~m} \mathrm{~s}^{-1}$, within the mixed layer, as also captured by the wind profiler data. In contrast, a stratified colder air mass is distributed offshore and over the Chesapeake Bay. Note the slight inland shift of the colder air mass that could be attributed to the onshore advection of the oceanic air mass by the prevailing surface southeasterly flow or sea breezes. Of interest is the development of two local wind maxima $\left(>7 \mathrm{~m} \mathrm{~s}^{-1}\right)$ at $H$ $=200 \mathrm{~m}$ near the coastline and on the downwind side of the bay as a consequence of the shallow land-sea/bay temperature contrast. This local shallow flow variation could be seen, to a certain extent, from the wind profiler data between 1200 and 1800 LST (cf. Figs. 6a and 

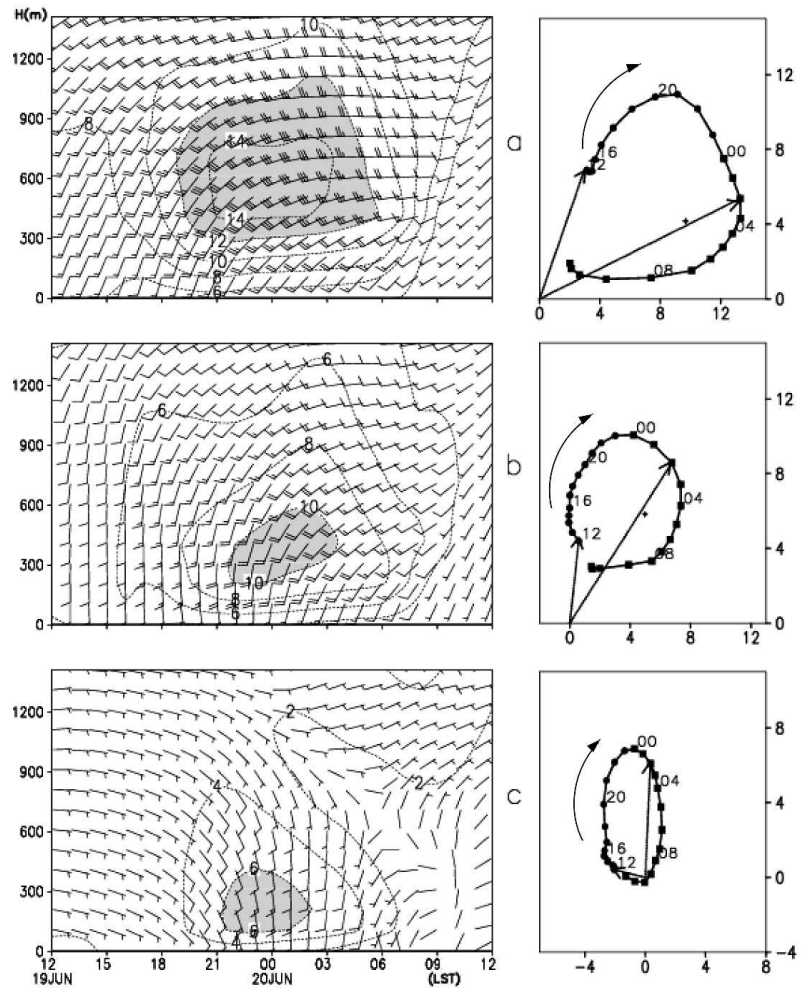
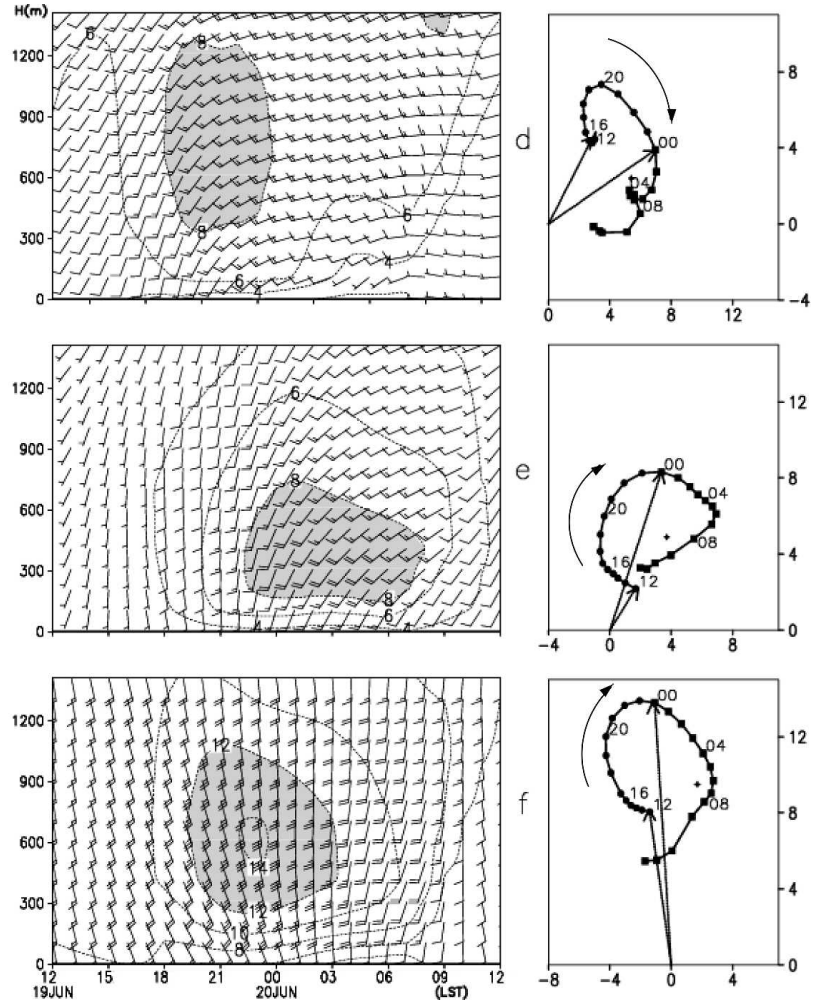

FIG. 8. As in Fig. 6, but for the (left) (28-52 h) modeled horizontal wind profiles and (right) (37-60 h) hodographs that are averaged over the $2^{\circ}$ lat $\times 2^{\circ}$ lon area at a few selected locations (i.e., at points A-F given in Fig. 7).

9a). Apparently, the low-level winds during the daytime could experience significant variations from the east coast to the peak of the Appalachians because of the land-sea and land-bay contrasts, as well as the sloping terrain effects.

While the low-level winds in the Mid-Atlantic states show substantial west-east variations during the daytime, there are pronounced diurnal changes over the region, especially after a shallow nocturnal inversion develops over land, roughly denoted by the $299-\mathrm{K}$ isentropic surface (Fig. 9b). For example, the wind direction has shifted from southerly during the daytime to southwesterly at night, but with little changes offshore (cf. Figs. 9a,b). In particular, an LLJ of $10-11 \mathrm{~m} \mathrm{~s}^{-1}$ is evident at the top of the surface-based inversion (i.e., $H$ $=300-400 \mathrm{~m}$ ), and it is peaked around $77.5^{\circ} \mathrm{W}$ along the sloping terrain. It is evident from Figs. $7 \mathrm{~b}, 8$, and $9 \mathrm{~b}$ that this LLJ, though loosely defined, has a width of $300-400 \mathrm{~km}$ (to its half-peak value) and a length of greater than $1500 \mathrm{~km}$. It appears after the horizontal thermal gradient between the sloping terrain and the neighboring air mass reverses its sign after sunset (cf. Figs. 9a,b), indicating the potential impact of topography on the generation of the LLJ, as hypothesized by Holton (1967). Note that the low-level southwesterly winds decrease in intensity eastward because of the reversed thermal gradient across the coastline from the mountain-generated thermal gradient. This suggests the possible contribution of the land-sea contrast to the LLJ development in terms of its preferred location. Note also that the amplitude of the mountain waves decreases as the atmospheric conditions become stabilized after sunset (cf. Figs. 9a,b), as indicated by weaker fluctuations in wind and temperature. It follows that the orientations of the Appalachians and coastline, as well as the diurnal variations of the west-east thermal gradients, explain well why the Mid-Atlantic LLJ tended to develop at the preferred location and altitude, mostly with southerly to westerly wind directions. Although the above findings remain to be generalized with more case studies, we may state that the wind profiler data collected at Fort Meade $\left(39.11^{\circ} \mathrm{N}\right.$, $76.71^{\circ} \mathrm{W}$ ) underestimated the intensity and even the frequency of LLJs. Nevertheless, many of the previous studies have also shown that the maximum intensity of the Great Plains LLJs tends to be located at the middle portion of the sloping terrain (e.g., Bonner 1968; Paegle and McLawhorn 1983; Zhong et al. 1996).

To gain further insight to the characteristics of the present LLJ, a diurnal cycle of the area-averaged tem- 

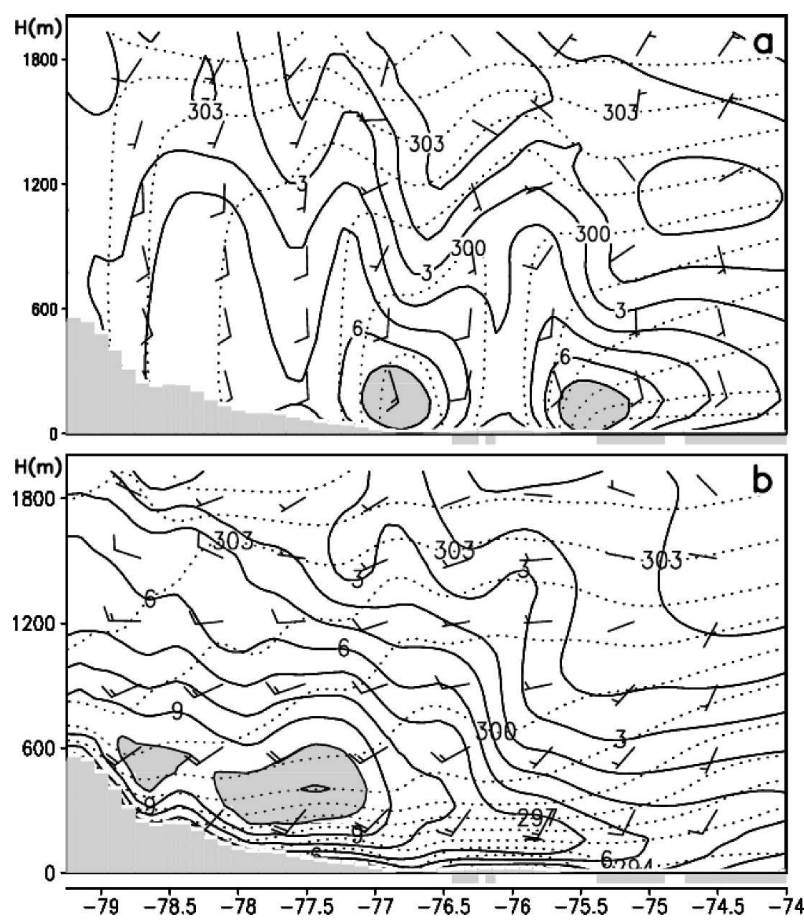

FIG. 9. Vertical (west-east) cross sections of horizontal velocity (solid lines are isotachs at intervals of $1 \mathrm{~m} \mathrm{~s}^{-1}$, and a full barb is 5 $\mathrm{m} \mathrm{s}^{-1}$ ) and potential temperature (dotted, every $1 \mathrm{~K}$ ) that are taken through Fort Meade (see Fig. 1 for the location) from (a) the 30-h integration valid at 1400 LST 19 Jun, and (b) the 42-h integration valid at 0200 LST 20 Jun 2001. The thick solid gray lines given at the bottom boundary denote the distribution of the water surface (i.e., sea or bay). Local wind maxima are shaded.

perature, horizontal wind, and geostrophic wind speeds at $H=500 \mathrm{~m}$ is given in Fig. 10, which shows that the geostrophic wind changes slightly in response to the diurnal variations of thermal winds induced by the terrain and land-sea contrast during this $24-\mathrm{h}$ period. However, the horizontal winds exhibit pronounced diurnal variations, that is, doubling from $5 \mathrm{~m} \mathrm{~s}^{-1}$ at noon to more than $10 \mathrm{~m} \mathrm{~s}^{-1}$ at midnight. The flows are subgeostrophic (by about 50\%) during the daytime as a result of the loss of horizontal momentum to the surface, and become highly supergeostrophic (by over $80 \%$ ) near midnight, followed by a decrease in magnitude, as dictated by the inertial oscillation theory. The results suggest that despite the absence of diabatic heating, the horizontal winds in the lowest $1-2 \mathrm{~km}$ could be highly ageostrophic in the presence of the surface heating and a sloping terrain.

\section{Sensitivity simulations}

We have seen from the preceding section the potential effects of the surface heating, the Appalachian

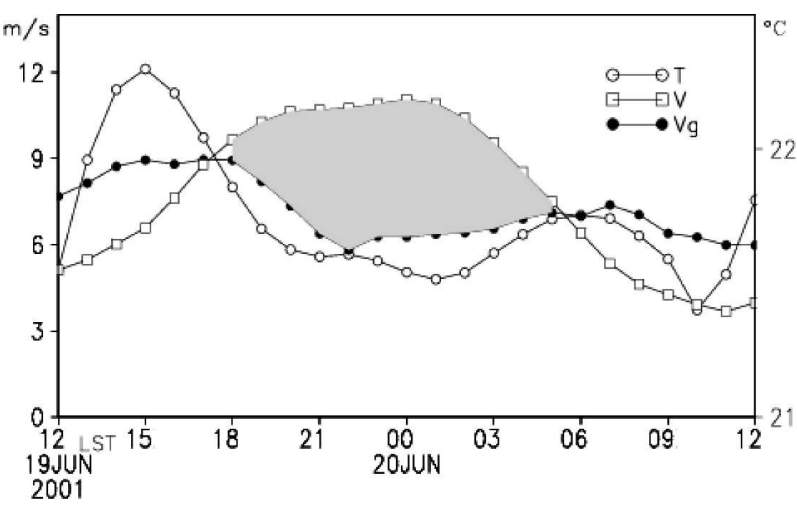

FIG. 10. Time series (LST) of the $2^{\circ}$ lat $\times 2^{\circ}$ lon area-averaged temperature $\left(T,{ }^{\circ} \mathrm{C}\right)$, the geostrophic wind speed $\left(V_{g}, \mathrm{~m} \mathrm{~s}^{-1}\right)$, and the horizontal wind speed $\left(V, \mathrm{~m} \mathrm{~s}^{-1}\right)$ at $500 \mathrm{~m}$ AGL over region B (see Fig. 7b) from the 28-52-h CTL simulation.

Mountains, and the land-sea contrast on the development of the LLJ over the Mid-Atlantic states. Thus, in this section, three 60-h sensitivity simulations of the modeled LLJs to the above parameters are performed using the results presented in section 4 as the control run (CTL). Time evolution of the area-averaged wind speeds at $H=500 \mathrm{~m}$ near Fort Meade and vertical cross sections of the mass and wind fields through the regions will be compared with the control results in order to quantify the contributions of the above-mentioned three parameters to the generation of the Mid-Atlantic LLJ.

First, the model's sensitivity to the surface heating is conducted by use of the temporally fixed surface temperatures from the model initial conditions (i.e., at 1200 UTC 18 June 2001); this is equivalent to a simulation in which the surface sensible and moisture fluxes are turned off (NFLX). In this case, a local wind maximum can still develop after midnight at an altitude and location close to those in CTL (cf. Figs. 11a and 9b). However, the peak magnitude is about half of the controlsimulated magnitude. This result confirms Blackadar's (1957) theory and reveals the importance of surface sensible and moisture fluxes in the development of the Mid-Atlantic LLJ. The horizontal winds to the west even become much weaker than those in CTL because of the presence of different stratifications in the two simulations, that is, the "dammed" cold air mass similar to that occurring during the winter season (Bell and Bosart 1988) versus the radiatively generated inversion along the sloping terrain (cf. Figs. 11a and 9b). Of interest is that unlike the control-simulated maximum, the local wind maximum does not occur near the top of the surface-based inversion, but within the stable PBL, which remains almost the same in structure and strength as that at the model initial time. The preferred 

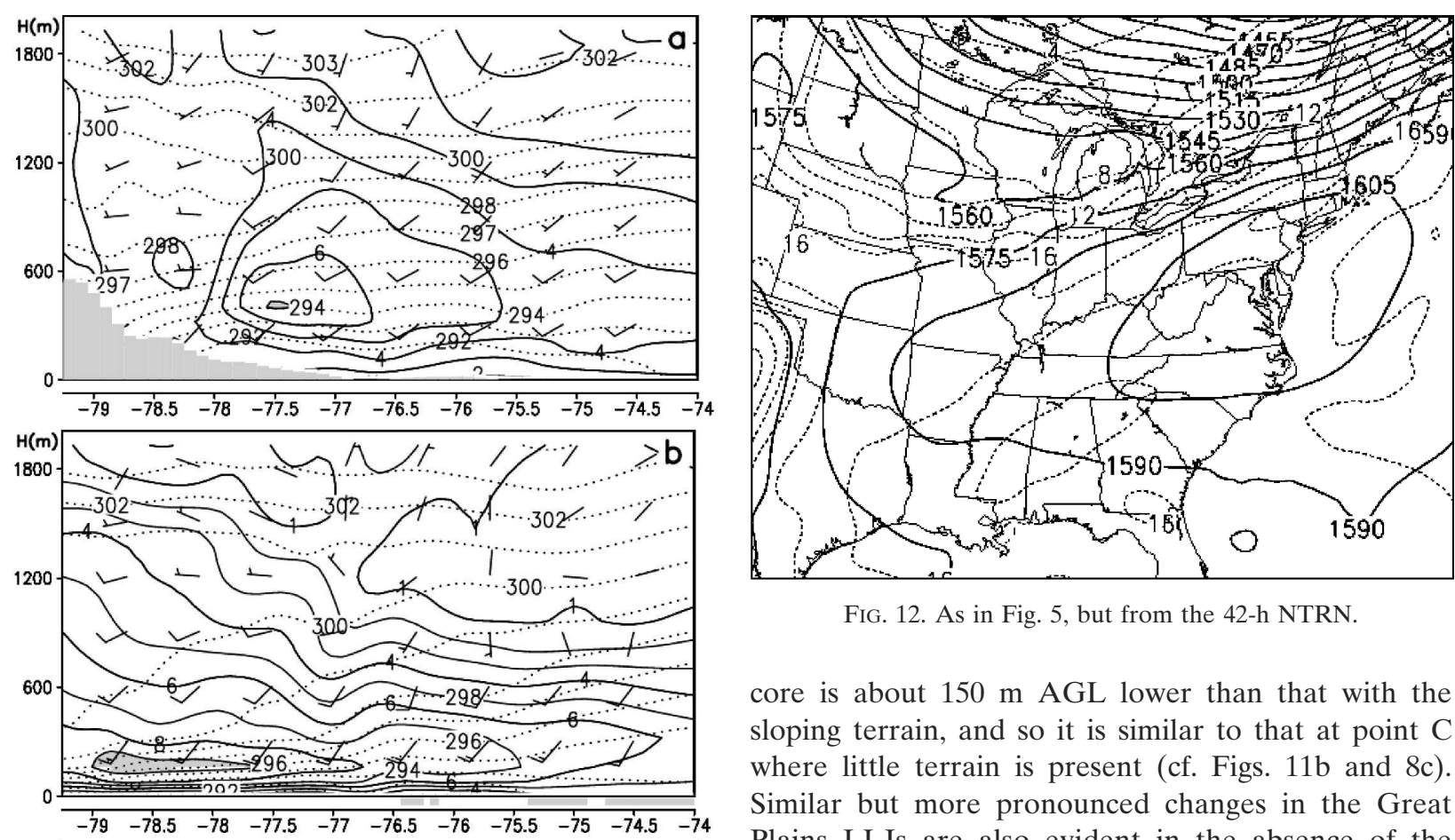

FIG. 12. As in Fig. 5, but from the 42-h NTRN.

core is about $150 \mathrm{~m}$ AGL lower than that with the sloping terrain, and so it is similar to that at point $\mathrm{C}$ where little terrain is present (cf. Figs. 11b and 8c). Similar but more pronounced changes in the Great Plains LLJs are also evident in the absence of the Rocky Mountains (not shown). Thus, the general results are qualitatively consistent with the previous theoretic and modeling studies showing that the roles of topography are to enhance the intensity of LLJs and elevate their altitudes (e.g., Wexler 1961; Holton 1967; McNider and Pielke 1981; Paegle and McLawhorn 1983; Pan et al. 2004).

Note that the local wind maximum is located about $100 \mathrm{~km}$ to the west of the control-simulated maximum. Figure 12 shows that this westward shift is associated with the westward extension of the subtropical high in the absence of the Appalachians. This result is consistent with a recent regional modeling study of the topographical effects on the Great Plains LLJs by Pan et al.

location and altitude of the LLJ, regardless of the PBL development, suggest that some other processes, such as terrain and the land-sea contrast to be examined below, may be operative.

A second 60-h simulation is performed in which a flat terrain is introduced (NTRN). In so doing, the volume occupied by the model topography is replaced by the air mass with a lapse rate of $6.5^{\circ} \mathrm{C} \mathrm{km}^{-1}$. Presumably, the impact of this artificial modification of the bottom boundary condition should become relatively small after one diurnal cycle of the PBL development. This is one of the basic reasons why the first 28 -h model simulations are excluded in Figs. 5-12. In the absence of topography, the LLJ could also develop, but with a speed that is about $2 \mathrm{~m} \mathrm{~s}^{-1}$ weaker than that control simulated (Fig. 11b). In addition, the altitude of the LLJ (2004). They showed that when the Rocky Mountains are removed, the subtropical high extends much westward with a much weaker southerly flow over the Great Plains, leading to the development of much weaker LLJs.

A third sensitivity experiment is performed in which all of the water surfaces are treated in the same way as land surfaces in terms of the surface fluxes of heat and momentum (NSEA). Previous studies have shown that coastal regions are favorable for the formation of LLJs because of the contrasts in temperature, moisture availability, roughness, and albedo. Other such case studies have been previously conducted for the LLJ events that occurred along the California coast (e.g., Meitin and Stuart 1977; Sjostedt et al. 1990; Dorman and Winant 1995; Bielli et al. 2002). In the present case, eliminating the water surfaces produces the smallest changes in the 
mass and wind fields among the three sensitivity simulations, except for the more stable PBL over the ocean, as expected (cf. Figs. 11c and 9b). The LLJ in NSEA is about $2 \mathrm{~m} \mathrm{~s}^{-1}$ weaker and located at an altitude about $100 \mathrm{~m}$ below that in CTL; both appear to be attributable to the absence of more notable thermal gradients above $H=200 \mathrm{~m}$ (cf. Figs. 9b and 11c). It should be mentioned, however, that the two daytime local wind maxima near the shorelines, as shown in Fig. 9a, are absent in NSEA (not shown) because of the removed land-sea contrast.

Last, we quantify in Fig. 13 the relative importance of the surface heat fluxes, topography, and the land-sea contrasts in determining the diurnal cycle of the lowtropospheric winds. Removing the surface heat fluxes produces the most significant impact of the LLJ, and then topography and the land-sea contrast (in that order). The area-averaged LLJ intensity near midnight is reduced from $12 \mathrm{~m} \mathrm{~s}^{-1}$ in the control simulation to about $6 \mathrm{~m} \mathrm{~s}^{-1}$ in NFLX, $9 \mathrm{~m} \mathrm{~s}^{-1}$ in NTRN, and $10 \mathrm{~m} \mathrm{~s}^{-1}$ in NSEA. Only small differences in wind speed occur near noontime among all of the simulations. The diurnal variation of the NFLX flows is relatively small, following closely that of the geostrophic winds (cf. Figs. 10 and 13). This suggests the near-balanced flow conditions in the absence of the surface heat fluxes.

\section{Summary and conclusions}

In this study, the wind profiler data collected during the two warm seasons of May-September 2001 and June-August 2002 at Fort Meade, Maryland, are utilized to document the Mid-Atlantic LLJ and its associated characteristics. A total of 160 LLJ events were observed, ranging from 8 to $23 \mathrm{~m} \mathrm{~s}^{-1}$, or with an average speed of $14 \mathrm{~m} \mathrm{~s}^{-1}$. About $60 \%$ of them meet the typical LLJ definition of $12 \mathrm{~m} \mathrm{~s}^{-1}$. On average, an LLJ appeared on 20-25 days of each month during the 2001 warm season, and 15-19 days for the 2002 warm season, showing significant variability in frequency from year to year. Of the 160 events, about 109 LLJs or 91\% occurred between 0000 and 0600 LST; and 94 events or $59 \%$ had southerly to westerly directions. They appeared at an average altitude of $670 \mathrm{~m} \mathrm{AGL}$, with significant events concentrated around $400 \mathrm{~m}$, and about $15 \%$ of the events occurred above $1 \mathrm{~km}$.

The performance of MM5 in predicting the LLJ events is then evaluated by verifying statistically the daily real-time numerical weather forecasts against the wind profiler data. It is found that the real-time forecasts capture more than $88 \%$ of the LLJ events and reasonably well the LLJ intensities for both seasons. In general, the modeled LLJ statistics for the year of 2002 compare more favorably to those observed than those

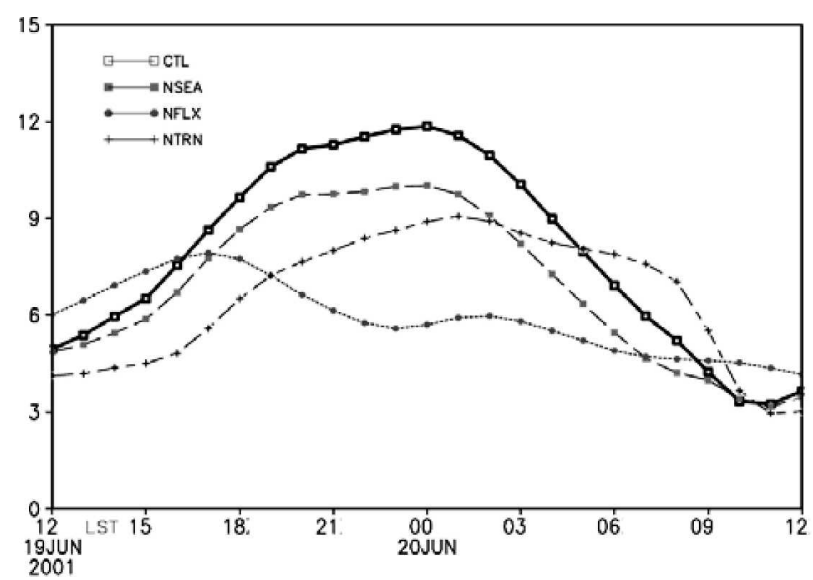

FIG. 13. Time series (LST) of the $2^{\circ}$ lat $\times 2^{\circ}$ lon area-averaged horizontal wind speeds at the LLJ level over region B (see Fig. 7b) from all of the 28-52-h sensitivity simulations (i.e., NFLX, NTRN, and NSEA) compared with the CTL simulation.

in 2001, likely because of the improved initial conditions associated with NCEP's daily analyses. A sizeable of the predicted LLJs also occur during 0000-0600 LST, and have southerly to westerly wind directions. The results show the sufficient ability of the model in predicting the LLJ occurrences in an operational setting, and help confirm the wind profiler-observed LLJ events with some unobservable characteristics.

A 60 -h modeling case study with three sensitivity simulations is finally performed to investigate the $3 \mathrm{D}$ structures and evolution of a Mid-Atlantic southwesterly LLJ and the mechanisms whereby it forms. Both the observations and the simulation exhibit a pronounced diurnal cycle of horizontal winds in the lowest $1.5 \mathrm{~km}$, with well-mixed, weak (subgeostrophic) flows during the daytime and (supergeostrophic) LLJs after midnight. Such a diurnal cycle is also evident over a significant portion of the United States, albeit with different amplitudes, depending upon the larger-scale dynamics and local topography. Although the MidAtlantic LLJ appears to be much weaker and less extensive than the Great Plains LLJs, it has a width of $300-400 \mathrm{~km}$ (to its half-peak value) and length of more than $1500 \mathrm{~km}$, and it follows closely the orientation of the Appalachians. The results can be explained by combining the theories of Blackadar (1957) and Holton (1967), with the mean shear effect included in estimating the inertial oscillation cycle.

It is found that the Appalachians tend to produce the sloping depth of the mixed layer with a northeasterly thermal wind component, and pronounced fluctuations in wind speeds in the vertical with larger shears near the PBL top during the daytime. With the additional landsea/bay contrasts, the daytime low-level winds could 
experience significant variations from the east coast to the mountainous regions. It is shown that the LLJ tends to be peaked preferentially around $77.5^{\circ} \mathrm{W}$, that is, in the middle portion of the sloping terrain, and it decreases eastward because of the opposite thermal gradients across the coastline from that mountaingenerated thermal gradient. This suggests that the wind profiler data collected at Fort Meade tend to underestimate the magnitude of the LLJs. Sensitivity simulations show that removing the surface heat fluxes produces the most significant impact of the LLJ, and then topography and the land-sea contrast, in that order. The $\left(2^{\circ} \times 2^{\circ}\right)$ area-averaged LLJ intensity is reduced from the control-simulated $12 \mathrm{~m} \mathrm{~s}^{-1}$ to about 6,9 , and $10 \mathrm{~m} \mathrm{~s}^{-1}$ in the absence of surface heating, terrain, and the land-sea contrast, respectively. Because of the significant sensitivity of surface heat fluxes, we may anticipate the important roles of soil moisture, roughness, albedo, and land use in modifying the intensity and structures of LLJs or the low-level flows in general.

In conclusion, LLJs with typical intensity and mesoscale characteristics could occur frequently during the warm season at some preferred locations over the MidAtlantic states. With the continued improvements in the model initial conditions and physical parameterizations, we should expect more accurate prediction of the LLJ events and daily weather conditions by the existing real-time forecasts and operational models in many institutions. The surface heat fluxes, the Appalachians Mountains, and the land-ocean/bay contrasts all play an important role in determining the intensity, orientation, and 3D location of the LLJs, as well as the spatial and diurnal variations of the lower-tropospheric flows from the east coast to the mountainous regions.

Of course, more observational and modeling case studies need to be performed to generalize the above conclusions during both summer and spring seasons. In particular, some effort should be made to collect more observations in high temporal and spatial resolutions at a location about $100 \mathrm{~km}$ to the west of Fort Meade in order to better capture the core of many LLJ events.

Acknowledgments. We are thankful to Maryland's Department of Environment (MDE) for providing the wind profiler data and to our colleagues in the UMDMDE Regional Atmospheric Measurement Modeling and Prediction Program for their enthusiastic support for this study. This work was supported by MDE's grant to UMD, and NSF Grant ATM-0342363.

\section{REFERENCES}

Arritt, R. W., T. D. Rink, M. Segal, D. P. Todey, C. A. Clark, M. J. Mitchell, and K. M. Labas, 1997: The Great Plains low- level jet during the warm season of 1993. Mon. Wea. Rev., 125, 2176-2192.

Augustine, J. A., and E. J. Zipser, 1987: The use of wind profilers in a mesoscale experiment. Bull. Amer. Meteor. Soc., 68, 4-17.

Bell, G. D., and L. F. Bosart, 1988: Appalachian cold-air damming. Mon. Wea. Rev., 116, 137-161.

Bielli, S., P. Barbour, R. Samelson, E. Skyllingstad, and J. Wilczak, 2002: Numerical simulations of the diurnal cycle along the Oregon coast during summertime northerly flow. Mon. Wea. Rev., 130, 992-1008.

Blackadar, A. K., 1957: Boundary layer wind maxima and their significance for the growth of nocturnal inversions. Bull. Amer. Meteor. Soc., 38, 283-290.

Bonner, W. D., 1968: Climatology of the low- level jet. Mon. Wea. Rev., 96, 833-850.

Bosart, L. F., and F. Sanders, 1981: The Johnstown flood of July 1977: A long-lived convective system. J. Atmos. Sci., 38, 1616-1642.

Dorman, C. E., and C. D. Winant, 1995: Buoy observations of the atmosphere along the west coast of the United States, 19811990. J. Geophys. Res., 100, $16029-16044$.

Dudhia, J., 1989: Numerical study of convection observed during the winter monsoon experiment using a mesoscale twodimensional model. J. Atmos. Sci., 46, 3077-3107.

Enfield, D. B., 1981: Thermally driven wind variability in the planetary boundary layer above Lima, Peru. J. Geophys. Res., 86, 2005-2016.

Farquharson, J. S., 1939: The diurnal variation of wind over Tropical Africa. Quart. J. Roy. Meteor. Soc., 65, 165-183.

Fast, J. D., and M. D. McCorcle, 1990: A two-dimensional numerical sensitivity study of the Great Plains low-level jet. Mon. Wea. Rev., 118, 151-163.

Higgins, R. W., Y. Yao, E. S. Yarosh, J. E. Janowiak, and K. C. Mo, 1997: Influence of the Great Plains low-level jet on summertime precipitation and moisture transport over the central United States. J. Climate, 10, 481-507.

Hoecker, W. L., 1963: Three southerly low-level jet systems delineated by the Weather Bureau special pibal network of 1961. Mon. Wea. Rev., 91, 573-582.

Holton, J. R., 1967: The diurnal boundary layer wind oscillation above sloping terrain. Tellus, 19, 199-205.

Kain, J. S., and J. M. Fritsch, 1990: A one-dimensional entraining/ detraining plume model and its application in convective parameterization. J. Atmos. Sci., 47, 2784-2802.

Maddox, R. A., 1983: Large-scale meteorological conditions associated with midlatitude mesoscale convective complexes. Mon. Wea. Rev., 111, 1475-1493.

Mass, C., and Y.-H. Kuo, 1998: Regional real-time numerical weather prediction: Current status and future potential. Bull. Amer. Meteor. Soc., 79, 253-263.

McNider, R. T., and R. A. Pielke, 1981: Diurnal boundary-layer development over sloping terrain. J. Atmos. Sci., 38, 21982212.

Means, L. L., 1944: The nocturnal maximum occurrence of thunderstorms in the Midwestern states. University of Chicago Miscellaneous Rep. 16, 38 pp.

Meitin, R. J., and D. W. Stuart, 1977: The structure of the marine inversion in northwest Oregon during 26-30 August 1973. Mon. Wea. Rev., 105, 748-761.

Mitchell, M. J., R. W. Arritt, and K. Labas, 1995: A climatology of the warm season Great Plains low-level jet using wind profiler observations. Wea. Forecasting, 10, 576-591. 
Mo, K. C., J. Nogues-Paegle, and J. Paegle, 1995: Physical mechanisms of the 1993 summer floods. J. Atmos. Sci., 52, 879-895.

Paegle, J., and D. W. McLawhorn, 1983: Numerical modeling of diurnal convergence oscillations above sloping terrain. Mon. Wea. Rev., 111, 67-85.

Pan, Z., M. Segal, and R. W. Arritt, 2004: Role of topography in forcing low-level jets in the central United States during the 1993 flood-altered terrain simulations. Mon. Wea. Rev., 132, 396-403.

Parish, T. R., A. R. Rodi, and R. D. Clark, 1988: A case study of the summertime Great Plains low-level jet. Mon. Wea. Rev., 116, 94-105.

Sjostedt, D. W., J. T. Sigmon, and S. J. Colucci, 1990: The Carolina nocturnal low-level jet: Synoptic climatology and a case study. Wea. Forecasting, 5, 404-415.

Stensrud, D. J., 1996: Importance of low-level jets to climate: A review. J. Climate, 9, 1698-1711.

Uccellini, L. W., and D. R. Johnson, 1979: The coupling of upper and lower tropospheric jet streaks and implications for the development of severe convective storms. Mon. Wea. Rev., 107, 682-703.

Wallace, M. J., 1975: Diurnal variations in precipitation and thunderstorm frequency over the conterminous United States. Mon. Wea. Rev., 103, 406-419.
Wexler, H., 1961: A boundary layer interpretation of the low level jet. Tellus, 13, 368-378.

Whiteman, C. D., X. Bian, and S. Zhong, 1997: Low-level jet climatology from enhanced rawinsonde observations at a site in the southern Great Plains. J. Appl. Meteor., 36, 1363-1376.

Zemba, J., and C. A. Friehe, 1987: The marine atmospheric boundary layer jet in the Coastal Ocean Dynamics Experiment. J. Geophys. Res., 92, 1489-1496.

Zhang, D.-L., 1989: The effect of parameterized ice microphysics on the simulation of vortex circulation with a mesoscale hydrostatic model. Tellus, 41A, 132-147.

- and R. A. Anthes, 1982: A high-resolution model of the planetary boundary layer-Sensitivity tests and comparisons with SESAME-79 data. J. Appl. Meteor., 21, 1594-1609.

_, and J. M. Fritsch, 1986: Numerical simulation of the mesobeta-scale structure and evolution of the 1977 Johnstown flood. Part I: Model description and verification. J. Atmos. Sci., 43, 1913-1943.

—, and W.-Z. Zheng, 2004: Diurnal cycles of surface winds and temperatures as simulated by five boundary layer parameterizations. J. Appl. Meteor., 43, 157-169.

Zhong, S., J. D. Fast, and X. Bian, 1996: A case study of the Great Plains low-level jet using wind profiler network data and a high-resolution mesoscale model. Mon. Wea. Rev., 124, 785806. 